This document was prepared in conjunction with work accomplished under Contract No. DE-AC09-96SR18500 with the U. S. Department of Energy.

\title{
DISCLAIMER
}

This report was prepared as an account of work sponsored by an agency of the United States Government. Neither the United States Government nor any agency thereof, nor any of their employees, nor any of their contractors, subcontractors or their employees, makes any warranty, express or implied, or assumes any legal liability or responsibility for the accuracy, completeness, or any third party's use or the results of such use of any information, apparatus, product, or process disclosed, or represents that its use would not infringe privately owned rights. Reference herein to any specific commercial product, process, or service by trade name, trademark, manufacturer, or otherwise, does not necessarily constitute or imply its endorsement, recommendation, or favoring by the United States Government or any agency thereof or its contractors or subcontractors. The views and opinions of authors expressed herein do not necessarily state or reflect those of the United States Government or any agency thereof. 


\section{Post Fire Transient Temperature Distribution in Drum Type Packages}

by

ALLEN SMITH

Westinghouse Savannah River Company

Savannah River Site

Aiken, South Carolina 29808

Additional Authors:

This paper was prepared in connection with work done under the above contract number with the U. S. Department of Energy. By acceptance of this paper, the publisher and/or recipient acknowledges the U. S. Government's right to retain a nonexclusive, royalty-free license in and to any copyright covering this paper, along with the right to reproduce and to authorize others to reproduce all or part of the copyrighted paper. 


\title{
Put Paper Number Here
}

\section{POST FIRE TRANSIENT TEMPERATURE DISTRIBUTION IN DRUM TYPE PACKAGES}

\author{
Allen C. Smith \\ Savannah River National Laboratory \\ Westinghouse Savannah River Company \\ Aiken, South Carolina 29808 \\ (803) 725 2943, allen.smith@srnl.doe.gov
}

\begin{abstract}
This study investigates the temperature distribution in an idealized cylindrical package subjected to the HAC Fire transient. Cases for several common overpack materials, with thermal conductivity spanning two orders of magnitude, are considered. The results show that the interior temperature distribution and maximum interior temperature are determined by the heat generation of the contents and the thermal resistance of the package materials. Heat generation has a dominant effect on the peak temperature in the center (containment vessel region) of the package, when the internal thermal resistance is high. For cases where the internal resistance is low, heat conducted into the interior during the fire determines the peak temperature in the center, containment vessel region. The thermal wave effect, where the interior temperature continues to rise after the end of the fire exposure, is present in all cases. The study complements the parametric studies of effects of thermal properties on thermal response of packages which were previously reported.
\end{abstract}

\section{INTRODUCTION}

The principal objective of design features of radioactive materials packages is to insure that the fundamental package performance requirements of containment, subcriticality and shielding are maintained during both normal and accident conditions which might be encountered in transport. The radioactive material is placed within a containment vessel, to protect against loss and dispersion. The containment vessel is typically enclosed in a protective overpack to prevent mechanical damage to the containment envelop and to insulate the containment vessel against overheating during a fire.

Welded closures for containment vessels are highly effective, being resistant to mechanical damage, and essentially proof against fire damage. However, welded vessels are limited to one-time-use, and are consequently justifiable only for highly sensitive contents. Re-useable containment vessels employ a bolted or threaded closure, with gasket or O-ring seals to insure the closure meets the containment requirement. Such seals are vulnerable to overheating during a fire event or as a result of internal heat generation. To protect the package against overheating of the closure seals or over-pressurization due to high internal temperature, the overpack must insulate against the heat transfer from the fire and, simultaneously, allow transfer of heat generated by radioactive decay from the package.

The regulatory thermal performance requirements for the package, in the United States, are specified by the Code of Federal Regulations, Title 10, Part 71, which implements IAEA requirements. $10 \mathrm{CFR} 71$ requires that the surface temperature of accessible parts of the package must remain less than $50^{\circ} \mathrm{C}\left(122^{\circ} \mathrm{F}\right.$ ), for general commerce (or $82^{\circ} \mathrm{C}$ for exclusive use) under steady state conditions without solar irradiation. The package must also be demonstrated to withstand the Hypothetical Accident Condition (HAC) fire test. This test requires exposure of the package to a fully enveloping fire $\left(800^{\circ} \mathrm{C}\right.$ flame temperature) for 30 minutes, with the ambient temperature before and after the fire at $38^{\circ} \mathrm{C}$. The 
package can be shown to meet these requirements by test or analysis. In practice, an instrumented fire test is usually required.

\section{THERMAL MANAGEMENT OF RADIOACTIVE MATERIAL PACKAGES}

The design of radioactive materials packages typically incorporates one or more containment vessels which, in turn, contain convenience canisters for the radioactive material. The containment vessel is enclosed within an overpack which provides impact absorbing capability as protection against mechanical damage as well as thermal insulation capability as protection against a fire. The overpack is enclosed within an outer shell which protects the overpack material against handling and environmental damage. This nested arrangement complicates the thermal management of the package. In the absence of heat generation, thermal protection of a package requires only that sufficient thickness of thermal insulation be provided to insure that the termperatures of critical interior components, such as O-rings, remain low enough to avoid damage. With heat generation, the thermal design of a package must provide for heat removal to minimize steady state internal temperature, but also minimize heat transfer into the interior during the fire event, to protect critical interior components.

Thermal properties of the package overpack materials largely determine the package's performance in fires. Because of the interactions of thermal properties, internal heat generation and external fire and cool down cycle, the thermal response of packages is not intuitively obvious.

Thermal analyses reported in the literature typically address a particular package, and how the thermal modeling was done to confirm that HAC Fire test requirements were met ${ }^{(1-4)}$. Parametric studies of the effects of thermal properties on thermal response of an idealized cylindrical package, with and without heat generation, showed that the peak internal temperature and associated response time, following the regulatory fire exposure, are determined by the relative surface and internal thermal resistances ${ }^{(5-6)}$.

This study considers temperature distributions in representative packages at various times before and following an HAC fire event. These results complement the previously reported parametric studies ${ }^{(5-6)}$. The temperature distributions presented here are additional data generated in the course of the parametric studies.

\section{ANALYSIS}

For the purpose of studying the effect of overpack properties on thermal response of a package, a simple one dimensional finite difference transient model was employed. The package was assumed to consist of a cylindrical interior region, $20.3 \mathrm{~cm}$ in diameter, which contained a heat generating material, surrounded by an annular layer of overpack material having an outside diameter of $35.6 \mathrm{~cm}$, Figure 1. This models the essential characteristics to the widely used drum packages in which the containment vessel is enclosed within a cane fiberboard overpack, as well as some other cylindrical packages. Heat generation was assumed in the inner, containment vessel region. A fairly high value of heat generation of 100 watts, was used for this study. Combined convection and radiation at the outer surface was assumed. The change from steady state to fire and then to post fire cool down was imposed by changing the heat transfer coefficient and environmental temperature at this boundary.

The drum is omitted from this simplified model. To account for the absence of the drum (which acts as a radiation shield in the fire test), a reduced value of heat transfer coefficient $\left(30 \mathrm{w} / \mathrm{m}^{\circ} \mathrm{K}\right)$ was employed for the fire exposure period of the analysis.

The interior of such packages is typically a complex structure, from a thermal perspective, with multiple walls separated by gaps or contact interfaces. The constant-heatgeneration interior condition imposes, under steady state, a thermal gradient at the outer surface of the interior assembly that is independent of the details of the interior containment vessel and contents configuration. The thermal resistances, specific heats, masses of materials, and heat generation rate determine the rate of response and magnitude of temperature rise of the contents when the steady state condition is changed by exposure to the HAC fire event. These interior characteristics also determine the magnitude of the deviation of the thermal gradient at the interface between the interior region and the overpack, from its steady state value, during the transient. However, the qualitative behavior is not changed by variations in these interior characteristics. For this parametric study of the effects of the overpack properties on package thermal response, the interior properties need only to be the same for each case.

Using this model, a parametric study of the effects of thermal properties of the overpack material on the temperature distribution within the package was performed. Five representative overpack materials, spanning a range in thermal conductivity of around two orders of magnitude, were considered. The packaging materials considered in this study, and their thermal properties, are shown in Table 1.

\section{RESULTS AND DISCUSSION}

The results of the parametric studies are shown in Figures 2 through 6 . 
In each case, the initial, steady state temperature distribution is shown. The relative resistance of the inner, containment vessel region (within $8.6 \mathrm{~cm}$, here) and the outer, overpack region is reflected in the relative slope of the steady state temperature curves for these regions.

Figure 2 shows the temperature distributions for a package employing cork for the overpack material (thermal conductivity $\mathrm{k}=0.043 \mathrm{w} \cdot \mathrm{m}^{-1} \cdot{ }^{\circ} \mathrm{K}^{-1}$, thermal diffusivity $\alpha=$ $\left.5.83 \times 10^{-4} \mathrm{~m}^{2} \cdot \mathrm{hr}^{-1}\right)$. Cork has the lowest thermal conductivity evaluated in this parametric study, resulting in the highest steady state central region temperature. The thermal conductivity in the central region, which has uniform properties in this simplified model (thermal conductivity $\mathrm{k}=$ $1.0 \mathrm{w} \cdot \mathrm{m}^{-1} \cdot{ }^{\circ} \mathrm{K}^{-1}$, thermal diffusivity $\alpha=1.86 \mathrm{~m}^{2} \cdot \mathrm{hr}^{-1}$ ), is higher that that of the cork. Consequently, the steady state thermal gradient in the central region is lower than in the cork overpack. Upon exposure to the fire environment, the temperature at the outer surface rises to very nearly the fire temperature $\left(800^{\circ} \mathrm{C}\right)$. The temperature within the package, however, rises much more slowly, because of the low thermal conductivity. Six minutes $(0.1 \mathrm{hr})$ after termination of the fire, the surface temperature has dropped to below $200^{\circ} \mathrm{C}$, but the internal temperature is virtually unchanged from the level achieved during the fire. The resulting relatively high internal temperature results in continued heat transfer to the interior package as well as flow of heat outward to the package surface. This produces the thermal wave effect, causing internal temperatures to continue to increase after the package is removed from the fire. By thirty minutes $(0.5 \mathrm{hr})$ after the fire, this effect has dissipated and all heat transfer is outward. Because of the low thermal conductivity of the cork, the return to the steady state temperature distribution requires several hours. Through the transient, the central region temperatures remain essentially unchanged.

Figure 3 shows the temperature distributions for a package employing cane fiberboard (Celotex ${ }^{\circledR}$ ) for the overpack material (thermal conductivity $\mathrm{k}=0.059 \mathrm{w} \cdot \mathrm{m}^{-1} \cdot{ }^{\circ} \mathrm{K}^{-1}$, thermal diffusivity $\alpha=4.11 \times 10^{-4} \mathrm{~m}^{2} \cdot \mathrm{hr}^{-1}$ ). The response for the cane fiberboard overpack is similar to that of the cork overpack. Because of the somewhat higher thermal conductivity, the steady state central region temperature is lower. Like the cork overpack case, the steady state temperature gradient in the central region, for this model, is lower than in the Celotex ${ }^{\circledR}$ overpack. Like the cork package, upon exposure to the fire, the outer surface temperature rises to very nearly the fire temperature. Six minutes after termination of the fire, the temperature in the outer region of the package has dropped very significantly, but is higher that that for the cork package at the same time. This is because of the greater heat transfer into the package during the fire exposure, due to the higher thermal conductivity, and the greater thermal storage capacity (density x specific heat) of the cane fiberboard. The thermal wave effect is again apparent. Because of the increased energy stored within the overpack, the duration of the thermal wave effect is longer. The time required to return to steady state is also longer. Cane fiberboard being a good insulator, the central region tempertures remain essentially unchanged for this case.

Figure 4 shows the temperature distributions for a package employing polyurethane foam for the overpack material (thermal conductivity $\mathrm{k}=0.398 \mathrm{w} \cdot \mathrm{m}^{-1} \cdot{ }^{\circ} \mathrm{K}^{-1}$, thermal diffusivity $\alpha=8.90 \times 10^{-3} \mathrm{~m}^{2} \cdot \mathrm{hr}^{-1}$ ). The thermal conductivity of the polyurethane foam overpack is approximately an order of magnitude greater than that of cork. The higher thermal conductivity results in a significantly different thermal response history. At steady state, the central region temperature is much lower than that for the cork or Celotex ${ }^{\circledR}$ packages, because of the lower resistance for heat transfer radially through the package. The thermal conductivity of the central region is about twice that of the overpack, so that the difference in steady state temperature gradient, between the central region and the overpack region, is much less than in the cork and Celotex cases (Figures 1 and 2). During the fire event, the outer surface temperature rises to nearly the fire temperature. During this time, the low internal resistance results in significant heat transfer into the package, as indicated by the increase in temperature in the interior of the package. Upon termination of the fire, the surface temperature drops rapidly, as it does for the cork and Celotex ${ }^{\circledR}$ cases. The thermal energy stored in the overpack is transferred both radially inward and radially outward, (thermal wave effect). Consequently, the temperature continues to increase in the interior as the temperature in the outer region decreases. This process continues with the peak central region temperature being attained approximately 1.5 hours after the termination of the fire. The peak central region temperature attained is, nevertheless, much lower that the steady state temperature for the well insulated cases (e.g., cork).

Figure 5 shows the temperature distributions for a package employing polyethylene foam for the overpack material (thermal conductivity $\mathrm{k}=0.398 \mathrm{w} \cdot \mathrm{m}^{-1} .{ }^{\circ} \mathrm{K}^{-1}$, thermal diffusivity $\left.\alpha=8.90 \times 10^{-3} \mathrm{~m}^{2} \cdot \mathrm{hr}^{-1}\right)$. The thermal conductivity of the polyethylene foam overpack is only slightly different from that of polyurethane. As a result, thermal response history is very similar. At steady state, the central region temperature is virtually the same as for the polyurethane case (and much lower than that for the cork or Celotex ${ }^{\circledR}$ packages). Like the polyurethane case, the steady state temperature gradient in the central region is about half that in the poly ethylene overpack. As in the previous cases, during the fire event, the outer surface temperature rises to nearly the fire temperature. During this time, the low internal resistance results in 
significant heat transfer into the package, as indicated by the increase in temperature in the interior of the package. Upon termination of the fire, the surface temperature drops rapidly, much like the polyurethane case. However, because of the greater thermal storage capacity of the polyethylene compared to the polyurethane, temperatures at corresponding locations are somewhat higher at each time step than for the polyurethane case. The thermal energy stored in the overpack is transferred both radially inward and radially outward, (thermal wave effect). Consequently, the temperature continues to increase in the interior as the temperature in the outer region decreases. This process continues with the peak central region temperature being attained approximately 1.5 hours after the termination of the fire. As in the polyurethane case, the peak central region temperature attained is much lower that the steady state temperature for the well insulated cases (e.g., cork).

Figure 6 shows the temperature distributions for a package employing high density aluminum oxide for the overpack material (thermal conductivity $\mathrm{k}=5.02 \mathrm{w} \cdot \mathrm{m}^{-1} \cdot{ }^{\circ} \mathrm{K}^{-1}$, thermal diffusivity $\alpha=18 \times 10^{-3} \mathrm{~m}^{2} \cdot \mathrm{hr}^{-1}$ ). The thermal conductivity of the high density aluminum oxide overpack is approximately an order of magnitude greater than that of polyurethane. The higher thermal conductivity results in a significantly different thermal response history. At steady state, the central region temperature is lower than that for the polyurethane or polyethylene packages, because of the lower resistance for radial heat transfer. The thermal conductivity of the overpack is about five times that of the central region (for this model), so that the steady state temperature gradient in the central region is greater than that in the overpack region. During the fire event, the outer surface temperature approaches the fire temperature, though not as closely as for the cases for lower thermal conductivity. During the fire exposure, the low internal resistance results in significant heat transfer into the package, as indicated by the increase in temperature in the interior of the package. Upon termination of the fire, the surface temperature drops. However, because of the outward transfer of thermal energy stored within the overpack, the rate of decrease is significantly less than in the other cases considered here. For example, six minutes after the termination of the fire, the surface temperature for the polyurethane package is approximately $200^{\circ} \mathrm{C}$, compared to $550^{\circ} \mathrm{C}$ for the high density oxide case. At 30 minutes after the fire, the surface temperature is approximately $360^{\circ} \mathrm{C}$. This slow cooldown is a result of the greater amount of thermal energy stored within the package during the fire. The relatively high conductivity results in rapid heat transfer into the package. The high thermal capacity (product of density and specific heat) enables storing of this thermal energy in the overpack. Consequently, the package cools slowly, falling to around $400 \mathrm{C}$ after 30 minutes, compared to less than $150^{\circ} \mathrm{C}$ for polyurethane after 30 minutes. As in the other cases, the thermal energy stored in the overpack during the fire is transferred both radially inward and radially outward. Consequently, the temperature continues to increase in the interior as the temperature in the outer region decreases. This process continues with the peak central region temperature being attained approximately one hour after the termination of the fire. The peak central region temperature attained is, nevertheless, lower that the steady state temperature for the cork (well insulated) case and is comparable to that for the Celotex ${ }^{\circledR}$ case. This is because of the great amount of thermal energy conducted into the interior of the package.

The earlier studies ${ }^{(5,6)}$ showed that, for values of thermal conductivity in excess of $1 \mathrm{w} / \mathrm{m}^{\circ} \mathrm{K}$ (i.e., when the surface resistance is dominant), the temperature rise is almost entirely due to heat conduction, (which is superimposed on the contribution to temperature rise due to heat generation).

Comparison of the steady state internal temperatures for the five cases confirms that the peak center temperature under steady state conditions with the same heat generation rate is determined by the thermal conductivity of the overpack material. In actual drum-type packages, the overall thermal resistance associated with the interfaces between the overpack and containment vessel and the containment vessel and contents is fairly high, resulting in even higher center temperatures than those predicted by the simplified model considered here.

\section{CONCLUSIONS}

The central temperature of radioactive materials packages typically continue to increase for a significant period of time following the HAC fire event.

For well insulated packages, the fire event has little effect on the temperature of the containment vessel region. However, in a well insulated package with heat generation, steady state temperature in the central region will be high.

Use of overpack material with a higher thermal conductivity results in a lower peak steady state temperature. However, the magnitude of the change in central region temperature during the fire exposure is greater and the peak temperature is attained as a result of the fire event.

\section{APPLICABILITY TO OTHER PACKAGES}

The analysis reported here extends the previous studies and provides an example of expected behavior, for the HAC fire event, of typical radioactive materials package (e.g., the US DOT 6M specification package) for several overpack materials having a wide range of thermal properties. The 
results given here, used in conjunction with the earlier studies, would facilitate the interpretation of instrumented fire test results on packages of this general configuration. These analyses also provide a means of evaluating the results of calculations made using standard thermal codes, to determine if they are physically reasonable.

\section{DISCLAIMER}

This document was prepared in conjunction with work accomplished under Contract No. DE-AC09-96SR18500 with the U. S. Department of Energy. DISCLAIMER This report was prepared as an account of work sponsored by an agency of the United States Government. Neither the United States Government nor any agency thereof, nor any of their employees, nor any of their contractors, subcontractors or their employees, makes any warranty, express or implied, or assumes any legal liability or responsibility for the accuracy, completeness, or any third party's use or the results of such use of any information, apparatus, product, or process disclosed, or represents that its use would not infringe privately owned rights. Reference herein to any specific commercial product, process, or service by trade name, trademark, manufacturer, or otherwise, does not necessarily constitute or imply its endorsement, recommendation, or favoring by the United States Government or any agency thereof or its contractors or subcontractors. The views and opinions of authors expressed herein do not necessarily state or reflect those of the United States Government or any agency thereof.

\section{REFERENCES}

1. Shah, V.L.., "Estimation of Package Temperatures During Hypothetical Accident Thermal Test Conditions", Proceedings the 11th International Conference on the Packaging and Transportation of Radioactive Materials (P ATRAM '95), Vol. II, pp. 633-640, (1995).

2. Greiner, M., Shin, S., Faulkner, R.J., and Wirtz, R.A., "Transport Package Response to Severe Thermal Events, Part 1: Rail Package", International Journal of Radioactive Materials Transport, V 9, N0. 3,pp. 187-192, (1998).

3. Greiner, M., Faulkner, R.J., and Jin, Y.Y., "Transport Package Response to Severe Thermal Events, Part 2: Legal Weight Truck Cask", International Journal of Radioactive Materials Transport, V 9, N0. 3, pp. 193-198, (1998).

4. Hensel, S.J. and Gromada, R.J., "Hypothetical Accident Conditions Thermal Analysis of 5320 Package", Proceedings of Transportation and Storage of Radioactive Materials, ASME PV\&P Conference, PVP V332, pp. 37-40, (1996).

5. Smith, A. C., "Effect of Thermal Properties on Thermal Response of Packages", International Journal of Radioactive Materials Transport, V10, No. 4, pp. 241-246, (1999).

6. Smith, A. C., "Effect of Heat Generation on Thermal Response of Packages", International Journal of Radioactive Materials Transport, V10, No. 4, pp. 247-250, (1999).

7. Title 10 US Code of Federal Regulations, Part 71 Packaging and Transportation of Radioactive Materials.

\begin{tabular}{|c|c|c|}
\hline \multicolumn{3}{|c|}{$\begin{array}{l}\text { Table 1.Thermal Properties of } P \\
\text { Included in the Parametric Study }\end{array}$} \\
\hline \multirow[t]{2}{*}{ Material } & $\begin{array}{l}\text { Thermal } \\
\text { Conductivity }\end{array}$ & $\begin{array}{l}\text { Thermal } \\
\text { Diffusivity }\end{array}$ \\
\hline & $\mathrm{w} / \mathrm{m}^{\circ} \mathrm{K}$ & $\mathrm{m}^{2} / \mathrm{hr}$ \\
\hline Cork & 0.043 & $5.83 \times 10^{-4}$ \\
\hline Cane Fiberboard & 0.059 & $4.11 \times 10^{-4}$ \\
\hline Polyurethane & 0.398 & $8.90 \times 10-3$ \\
\hline Polyethylene & 0.414 & $6.91 \times 10^{-3}$ \\
\hline $\begin{array}{l}\text { High Density } \mathrm{Al} \\
\text { Oxide }\end{array}$ & 5.02 & $18 \times 10^{-3}$ \\
\hline
\end{tabular}

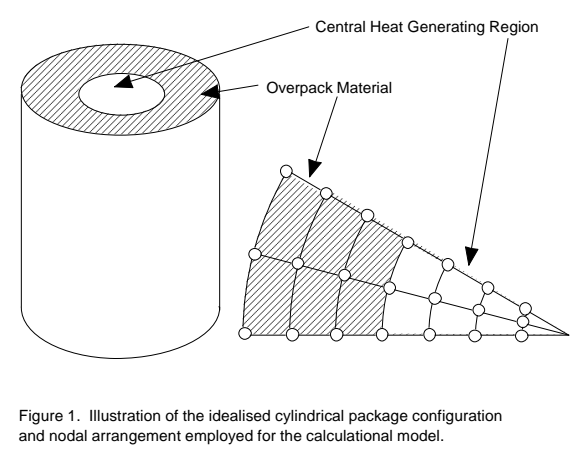




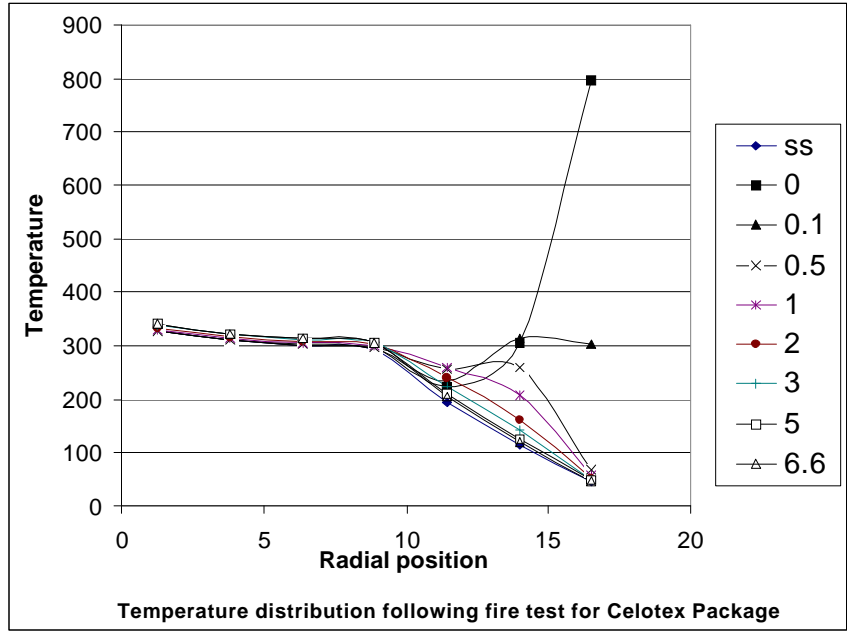

Figure 2.

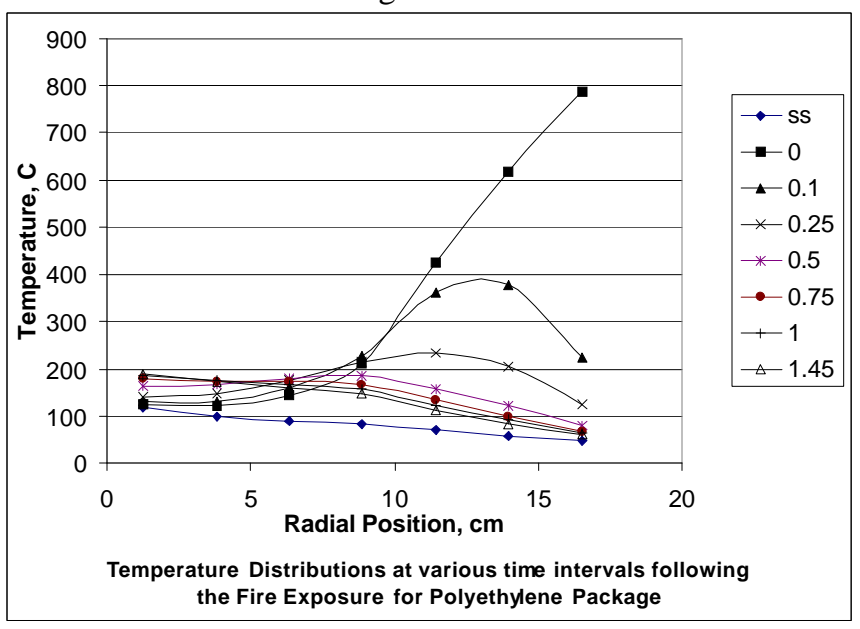

Figure 3.

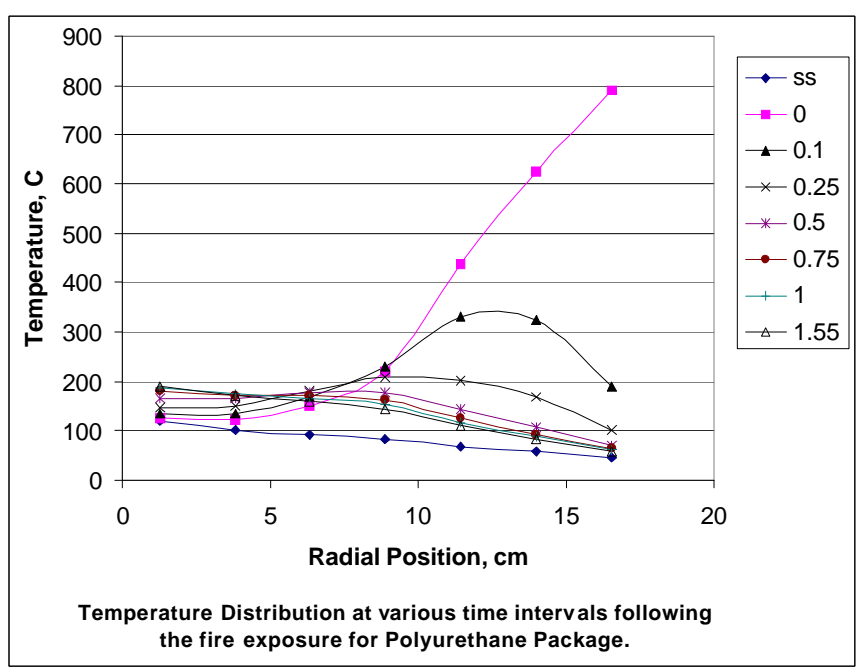

Figure 4.

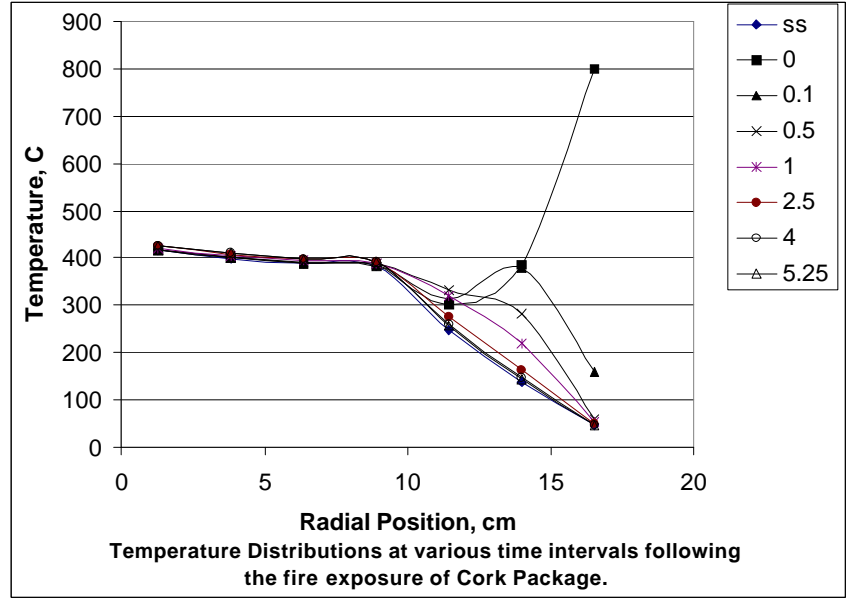

Figure 5.

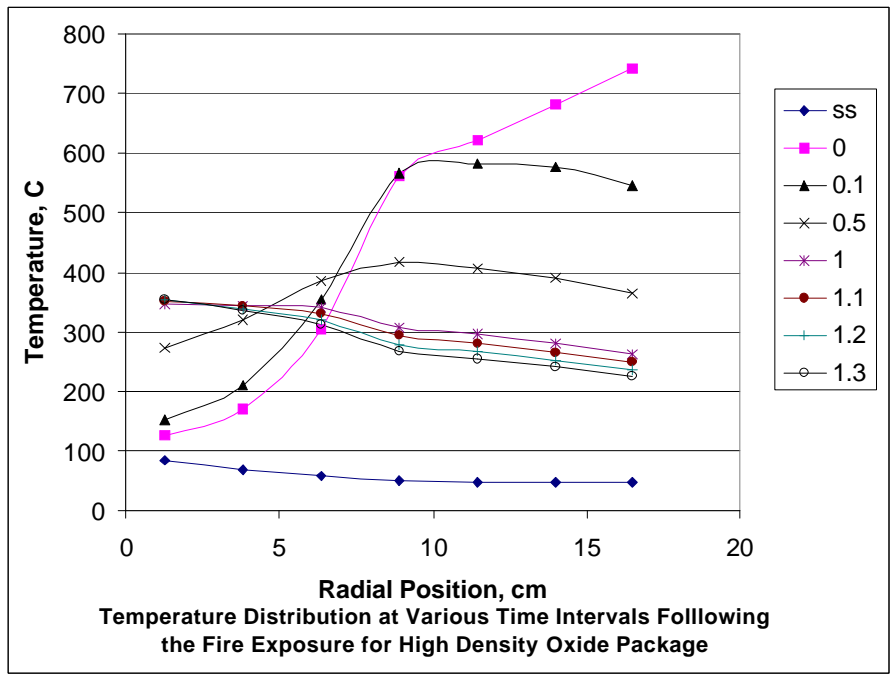

Figure 6. 